ARTICLE HISTORY: Received: September 05, 2021 Accepted: October 28, 2021 Published: November 04, 2021

УДК 629.44. $083(571.63)$

К ВОПРОСУ МОДЕРНИЗАЦИИ ПРОЦЕССА ПОГРУЗКИ УГЛЯ НА СТАНЦИЯХ

Лаптева И.И.

Дальневосточный государственный университет путей сообщения, Хабаровск, Россия,

89625017763

Карнаков Е.A.

Дальневосточный государственный университет путей сообщения,

Хабаровск

\title{
ON THE ISSUE OF MODERNIZATION OF THE COAL LOADING PROCESS AT THE STATIONS
}

\author{
Lapteva I.I. \\ Far Eastern State of Transport University, \\ Khabarovsk, 89625017763 \\ Karnakov E.A. \\ Far Eastern State of Transport University, \\ Khabarovsk
}

Аннотация. Рассматриваются проблемы, возникающие при перевозке угля по железной дороге со станции Новый Ургал, с предложением модернизации процесса погрузки, так как на существующих типах полувагонах или открытых контейнерах происходит выдувание из них угольной пыли и, как следствие, наблюдается загрязнение окружающей среды вокруг железной дороги.

Abstract. The problems arising during the transportation of coal by rail from the Novy Urgal station are considered, with a proposal to modernize the loading process, since coal dust is blown out of them on existing types of gondola cars or open containers and, as a result, pollution of the environment around the railway is observed.

Ключевые слова: угольная пыль, полувагоны, контейнеры, загрязнение окружающей среды, железная дорога.

Keywords: coal dust, gondola cars, containers, environmental pollution, railway.

ОАО "Ургалуголь" - крупнейшее угольное горнодобывающее предприятие на Дальнем Востоке, градообразующее предприятие села Чегдомын, которое занимает лидирующие позиции в экономике Верхнебуреинского района.

Но возникают проблемы при перевозке угля по железной дороге. В полувагонах или открытых контейнерах происходит выдувание из них угольной пыли и, как следствие, наблюдается загрязнение окружающей среды вокруг железной дороги. Кроме того, угольная пыль при выгрузке угля из вагона или открытого контейнера и его перегрузке в морские суда загрязняет всю территорию порта и прилегающие населенные пункты [ ].

Для устранения экологического загрязнения территорий уже разработаны различные конструкции контейнеров с закрытым объемом для перевозки и хранения сыпучих грузов. Однако применение известных закрытых контейнеров усложняет их погрузку и соответственно увеличивает время технологического цикла погрузки. Необходимо подобрать вариант контейнера, который сможет обеспечить снижение времени технологического цикла погрузочных работ без существенного увеличения себестоимости перевозки груза.

Универсальные контейнеры изготовляются, как правило, из стали, хотя всё большее применение находят лёгкие алюминиевые сплавы и пластмассы, не подверженные коррозии и не требующие окраски. Собственный вес таких контейнеров значительно меньше, что повышает их эффективность.

Крупнотоннажные контейнеры массой брутто 10;16;24;25,4 и 30,48т предназначены для бесперегрузочной доставки грузов преимущественно малотоннажными отправками, а среднетоннажные - мелкими отправками.

Для перевозки угля можно использовать контейнеры разного рода тоннажности, при этом эти контейнеры можно размещать как на платформах, так и на полувагонах.

Контейнеры среднего рода тоннажности могут быть перевезены как на платформах универсального типа, так и в полувагонах. Вместительность вагона будет составлять 11 контейнеров с массой брутто по 3 т, при данной погрузке нагрузка вагона - 33 т или же вместимость 5 контейнеров с массой по 5 т, тогда нагрузка вагона при транспортировке будет составлять 25 т. 
Если же погрузка вагона имеет смешанный тип, то вместимость контейнеров составляет от 6 до 10 контейнеров, а статическая нагрузка при этом варьируется от 26 до 32 т.

Контейнеры крупного рода тоннажности могут быть перевезены исключительно на платформах. Если платформа универсальная, то в ней возможно разместить 1 контейнер с массой брутто в 30 т или 2 контейнера с массой 24 т. Если же речь идет о специальной фитинговой платформе, то возможная вместимость будет составлять - один контейнер с массой брутто 30 т или три контейнера массой брутто 24 т.

Для перевозки контейнеров можно переоборудовать кузовную часть полувагонов, сделать их такой, чтобы можно было устанавливать и снимать контейнеры. Также для контейнерных перевозок можно использовать универсальные и специализированные платформы, комбинируя разную компоновку размещения контейнеров, но внедрение платформ существенно увеличивает затраты на перевозку.

Средняя длина вагона по концевым балкам рамы 13,5 м. Используя контейнеры СК2-15,длина которых 1,84 м, а нетто 14,6, на одном полувагоне можно разместить определенное количество контейнеров, рассчитанное по формуле:

$$
n=\frac{i_{\text {max }}}{i_{\text {WoII }}}
$$

где $\mathrm{n}$ - количество контейнеров типа СК2-15, которое возможно разместить на 1 вагоне; $\ell_{\text {ваг }}-$ средняя длина вагона; $\ell_{\text {комm }}$ - длина контейнера типа СК2-15.

$$
n=\frac{13,5}{1,84}=7,33 \approx 6 \text { контейнеров. }
$$

Из общего расчета - 1,33 контейнера или 2,44 м на невозможность установки контейнеров вплотную. Количество перевозимого груза находим по формуле:

$$
m=n \cdot p_{x}(2)
$$

где m - количество перевозимого груза; p - нетто контейнера.

$$
m=6 \cdot 14,6=87,6 \text { тонны. }
$$

Статическая нагрузка определяется по формуле:

$$
q=\frac{m}{z^{x}}
$$

где q - статическая нагрузка на ось; z - количество осей.

$$
q=\frac{86_{g} g}{4}=21,9 \mathrm{Tchaocb}
$$

Статическая нагрузка на ось равна 21,9 тс на ось и является допустимой нагрузкой для пути.

Известен контейнер для сыпучих грузов, который обеспечивает перевозку и хранение малотоннажных грузов в закрытом объеме [3].

Малотоннажный контейнер для сыпучих грузов, представляет собой прямоугольный корпус с днищем, с боковыми стенками и крышкой. Крышка закреплена шарнирно у верхнего края одной из продольных стенок контейнера. Крышка выполнена с возможностью поворота на угол более $90{ }^{\circ} \mathrm{C}$. В закрытом положении крышка контактирует с верхними торцами боковых стен контейнера. Данная конструкция применяется исключительно для малотоннажных контейнеров. Перед погрузкой крышка у контейнера вручную поднимается до вертикального положения, опускается до упора в боковую стенку, открывая контейнер. Вместе с этим крышка контейнера во время подъема занимает вертикальное положение, приводя к увеличению габаритной высоты контейнера на величину равную ширине крышки и габаритная высота контейнера получается равной

$$
\mathrm{H}_{\mathrm{r}-\mathrm{OKK}}=\mathrm{H}_{\mathrm{CKK}}+\mathrm{H}_{\mathrm{F}}
$$




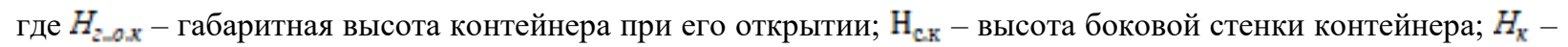
ширина крышки контейнера.

Уголь или другой сыпучий груз загружается в контейнер через открытый верхний проем. После окончания загрузки крышка контейнера вручную опускается до горизонтального положения, закрывая контейнер. Далее груз в контейнере хранится или перевозится. Причем груз полностью изолирован от окружающей среды и обеспечивается защита как груза от внешних осадков, так и защита окружающей среды от вредных частиц груза.

Увеличение габаритов малотоннажного контейнера в процессе погрузки и разгрузки контейнеров вписывается в габариты погрузочного устройства без усложнения технологии погрузочных работ.

Достоинством контейнера для сыпучих грузов является обеспечение защиты окружающей среды от угольной пыли вовремя перевозки и хранения груза.

Недостаток известного контейнера для сыпучих грузов заключается в его малотоннажности, что ограничивает возможности применения упомянутых контейнеров бо̀льшей тоннажности, габариты которых не смогут вписаться в габариты погрузочного устройства без усложнения технологии погрузочных работ.

Более близким по совокупности существенных признаков и достигаемому результату является контейнер для сыпучих грузов, который сможет обеспечить перевозку и хранение малотоннажных и среднетоннажных грузов в закрытом объеме [4].

Контейнер для сыпучих грузов работает следующим образом.

Фиксатор перед загрузкой освобождает крышку контейнера. Под действием упругой силы пружин каждая секция крышки поднимается, открывая контейнер. При этом секции крышки контейнера занимают вертикальное положение, что приводит к увеличению габаритной высоты контейнера на ширину секции крышки, равную половине ширины крышки, и габаритная высота контейнера в этом случае равна

$$
\mathrm{H}_{\mathrm{T}-\mathrm{OWK}}=\mathrm{H}_{\mathrm{CK}}+\frac{1}{2} \mathrm{H}_{\mathrm{K}}
$$

Данная высота контейнера, как малотоннажного, так и среднетоннажного, вписывается в габариты погрузочного устройства.

Уголь или другой сыпучий груз загружается в контейнер через открытый верхний проем.

Каждая секция крышки после загрузки контейнера при помощи, к примеру кранового оборудования из вертикального положения возвращается в горизонтальное положение, закрывая контейнер, Уже после закрытия крышки и ее фиксации в закрытом состоянии груз хранится или перевозится. При этом груз полностью изолирован от окружающей среды, что обеспечивает защиту как груза от атмосферных осадков, так и окружающей среды от вредных частиц груза.

Увеличение габаритов среднетоннажного контейнера в процессе его погрузки вписывается в габариты погрузочного устройства без усложнения технологии погрузочных работ.

Достоинством контейнера для сыпучих грузов является защита окружающей среды от угольной пыли вовремя перевозки и хранения груза. Другим достоинством является увеличение грузоподъемности контейнеров до среднетоннажных.

Однако увеличение тоннажности контейнеров, используемых для перевозки сыпучих грузов, остается недостаточным, так как ограничивает возможности применения контейнеров большой тоннажности, ведь их габариты не вписываются в габариты погрузочного устройства без усложнения технологии погрузочных работ.

Разработка маршрутной технологии для контейнеров, которые будут введены в технологический процесс и будут проследовать через станцию ПТО Новый Ургал, включает в себя выбор технологических операций для обработки заготовки, а также выбор последовательности выполнения этих операций. Маршрутная технология обработки контейнеров на станции Новый Ургал представлена на рисунке 1.

С введением маршрутной технологии, необходимо соблюдать требования к осмотру и ремонту контейнеров, регламентированные нормативной документацией и технологическим процессом в соответствии с выполняемым видом ремонта.

ТР выполняется на спецплощадке с эстакадой для ремонта и обслуживания оборудованным необходимым для этого оснащением, запасными частями. Осмотр контейнеров осуществляется перед погрузкой/выгрузкой осмотрщиками ремонтниками подвижного состава и, или приёмосдатчиком перед отправлением или пересылкой на контейнерный пункт, для этого на станции Новый Ургал необходимо введение такой площадки, что требует модернизации пункта, предложенного на рисунке 2.

Операции связанные с прицепкой и отцепкой вагонов относят к маневровым работам, которые регламентируются правилами технической эксплуатации ЖД Российской Федерации. Инструкцией на железнодорожном транспорте РФ по движению поездов и маневровой работе, регламентом организации маневровой работы и должностной инструкцией составителя поезда. 
Bсе операции на станционных путях проводятся по указанию только одного работника: дежурного по станции, маневрового диспетчера, дежурного по парку (сортировочной горке), а на участках, оборудованных диспетчерской централизацией, поездного диспетчера. В техническо - распорядительном акте станции указываются распределения обязанностей по маневровым работам.
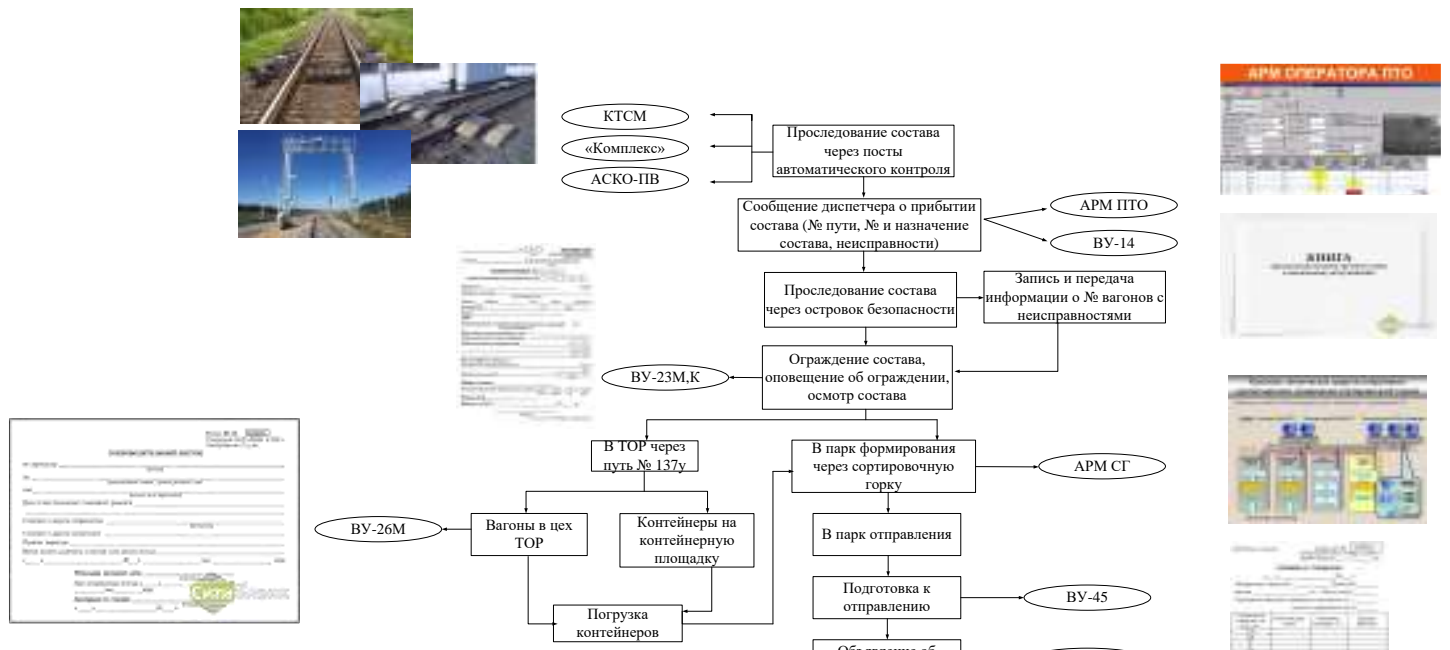

состава, неисправности)

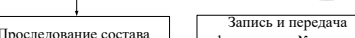
рез островок безопасности $\rightarrow$ информации о Ограждение состава, осмотр состава

$\left[\begin{array}{c}\text { В парк формирования } \\ \text { через сортировочную }\end{array}\right]$ АРМ СГ

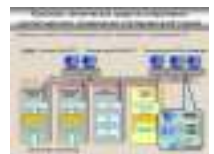
- через сортировочн
горку
-

i

В парк отправления

Подготовка к

отправлению

Объявление об
отправлении сост

отправлении состав

Движение состава н

погрузку

* Коммерческий осмотр контейнеров

осуществляется при отправлении со
станшии Чегдомын

Рис.1. Маршрутная карта обработки состава на станцฺии Новый Ургал после модернизации

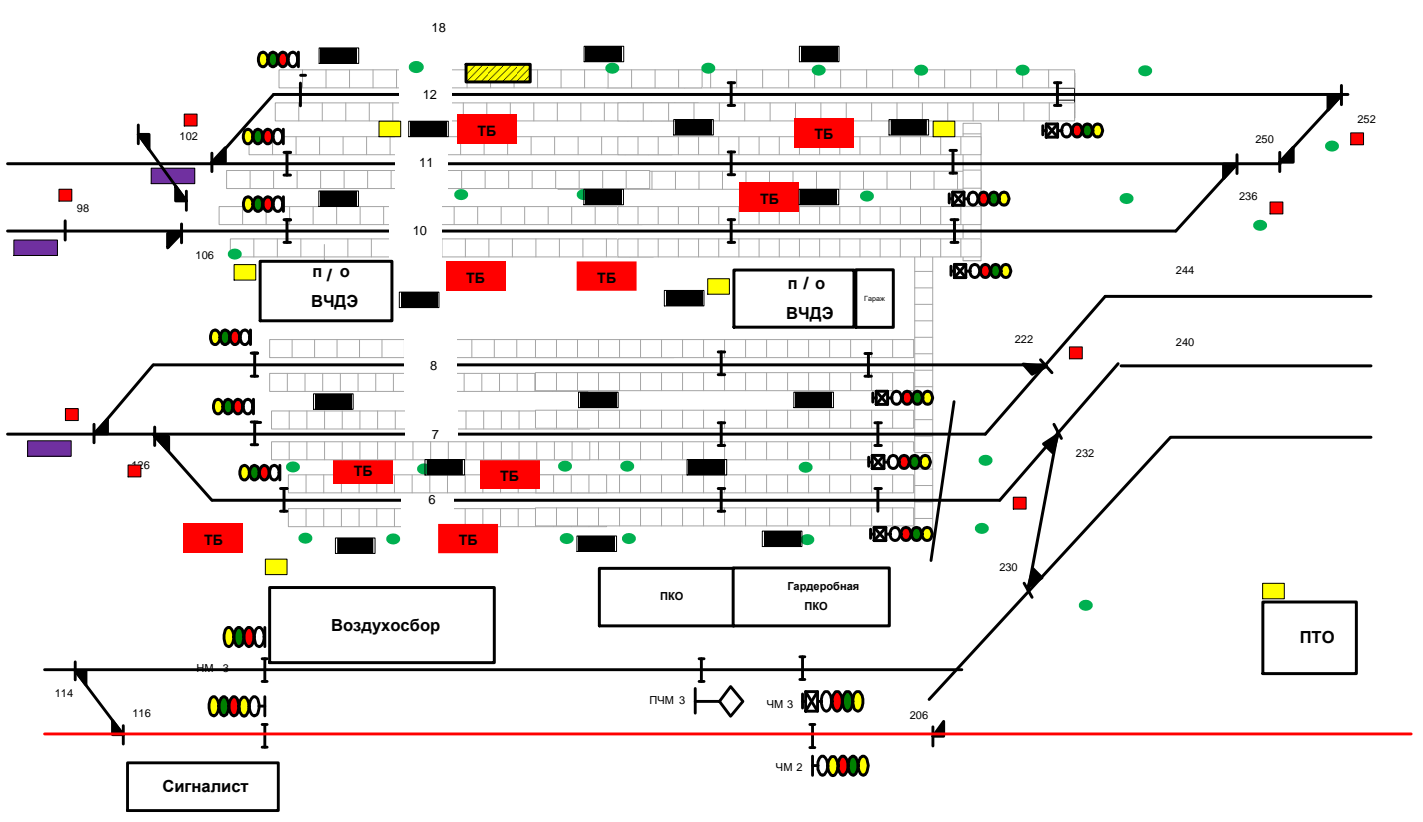

Рис.2. Схема приемоотправочного парка Новый Ургал после модернизации

За движением маневрового локомотива, отвечает - руководитель маневров или составитель поездов, который является ответственным за правильность их выполнения. При маневровой работе указания передаются через основное средство передачи информации - радиосвязь, в крайних случаях - устройства двухсторонней парковой связи. Также разрешена подача ручными сигнальными приборами.

При обнаружении в пункте технического обслуживания неисправностей вагона, которые устраняются только при текущем отцепочном ремонте, требуют отцепки и отцепка, как правило, осуществляется поездными или маневровыми локомотивами. Продолжительность маневровой работы, которая осуществляется с поездом, зависит от вида локомотива, которым выполняется маневровая работа и места производства отцепки вагонов от состава (в голове, середине или в хвосте состава), а также вида выполняемых операций. У маневрового локомотива свой график работы, в котором все распланировано по минутам и, чтобы дождаться отцепки 
необходимого вагона требуются вынужденные простои целого состава. Что в свою очередь тормозит процесс работы пункта технического обслуживания.

В качестве альтернативы, заменяющей работу маневровых локомотивов, можно рассмотреть машины на комбинированном ходу которые позволяют производить не только маневровые работы, но и проводить контроль и диагностику небольших участков пути, оперативно доставлять на места восстановительных работ ремонтные бригады с необходимым оборудованием.

Машины на комбинированном ходу с пневматическим управлением могут передвигаться как по автомобильным дорогам, так и по железнодорожной колее. Могут в течение 10 минут переходить с автомобильного хода на железнодорожный и обратно. Такие машины можно эксплуатировать в любое время года и при воздействии осадков.

\section{Список литературы:}

1. Зыков Ю.В., Козубенко И.Д., Лозинский С.Н. и др. Новая система технического обслуживания грузовых вагонов. // Железнодорожный транспорт, 2002, №1, с. 14-21.

2. Типовой технологический процесс работы пункта технического обслуживания грузовых вагонов сетевого значения. ТК-254 / МПС. - М.: Транспорт, 2012. - 136 с.

3. Патент 2178379 РФ, МПК В65D88/54, B65D88/00. Контейнер для сыпучих грузов / И.И.Демченко, В.Д.Буткин, С.В.Ивкин, С.Б.Васильев, А.И.Демченко (РФ). - № 2000115074/13; Заявлено 09.06.2000; Опубл. 20.01.2002.

4. Патент 2243140 РФ, МПК В65D88/54. Контейнер для сыпучих грузов / И.И.Демченко, В.Д.Буткин, С.В.Ивкин, С.Б.Васильев, А.И.Демченко (РФ). - № 2003101500/12; Заявлено 20.01.2003; Опубл. 27,12,2004. 